\title{
Extending the reach of the JLO
}

It has now been a year since we launched the new-look Journal of Laryngology \& Otology with full colour reproduction of illustrations and a re-designed article format. The resulting positive feedback has been very gratifying. Over the past year, there have been a number of additional initiatives within the JLO, which we hope will offer much added value to our readers and subscribers.

The principal exciting development has been a partnership with The Australian Society of Otolaryngology Head and Neck Surgery (ASOHNS). This will provide our Australian colleagues with electronic access to The Journal. In addition, an 'Australian Supplement' to the JLO will be published on a twice-yearly basis. The Editor of the 'Australian Supplement' will be Simon Carney, who will have access to articles previously published in the main JLO as well as commissioning articles directly from Australian authors. We at the JLO, and our ASOHNS colleagues, will be working hard to make this initiative a success. A large amount of work has been put into this project by Daniel Edwards, Guy Kenyon and Rosamund Greensted on the JLO side, and by Mark Carmichael, Michael Jay, Vince Cousins and Simon Carney in Australia. We see this development as an important way of making the content of the JLO available to as wide a readership as possible.

In 2011, we also saw the establishment of the JLO Best Paper Awards. The first presentation of these awards was administered by Desmond Nunez, with assistance from Musheer Hussain and Liam Flood. Journal of Laryngology \& Otology papers in various categories were assessed thoroughly against a number of criteria. The authors of the best papers were then invited to present their papers at a meeting at the Royal Society of Medicine in London, which was followed by a memorable dinner held on HMS Belfast, overlooking the River Thames. We were able to welcome authors from Denmark, South Korea and The Netherlands as well as the UK. The Best Paper Awards will continue in 2012, and we look forward to welcoming the winning authors again to the presentation event in May 2012.

We continue to develop the JLO website (www.jlo. co.uk), with the intention of creating a major educational resource for our subscribers. For many years our website partner has been Tell Communications, with whom we have enjoyed a long and fruitful partnership. We thank Simon Budd and his team at Tell Communications for their collaborative work over the past years. After exploring various options, we have decided to appoint a new website partner: Selesti. The JLO Web Editor, Vik Veer, aided by Andrew Chalk of Outside In Marketing, will be working with Selesti and our colleagues at Cambridge University Press on a new JLO website design, which will provide additional functionality for readers and authors.

As always, as journal editors we are reliant on our peer review system to maintain quality assurance. At present, the JLO accepts about one-third of papers submitted. We are indebted to our Assistant Editors, who undertake the task of reviewing the many papers submitted. In 2011, Alfio Ferlito, Pat Bradley and Alessandra Rinaldo stepped down as Assistant Editors, and we thank them for their work on behalf of The Journal. We have appointed new Assistant Editors, in Sean Carrie, Quentin Gardiner, Tristram Lesser, Vin Paleri, Peter Robb and Azhar Shaida.

As ever, we must thank our partners at Cambridge University Press, particularly Daniel Edwards, Susan Perkins and Charlotte Porter, for their work on behalf of the JLO. Finally, we continue to be indebted to the JLO's own administrative staff of Rosamund Greensted, Iona Copley and Lisa Colledge, without which the production of the JLO would not be possible.

ROBIN YOUNGS EDWARD FISHER Editors 